\title{
FAKTOR RESIKO YANG BERHUBUNGAN DENGAN TERJADINYA ULKUS DIABETIK PADA PENDERITA DIABETES MELITUS TIPE 2 DI RSUD SYEKH YUSUF KABUPATEN GOWA
}

Risk Factors Associated with the Occurrence of Diabetes Ulcers in Type 2 Diabetes Mellitus' Patients in Syekh Yusuf Hospital Gowa Regency

\author{
Saenab Dasong ${ }^{1}$, Suhartatik ${ }^{2}$, Arlin Afrianti $^{3}$ \\ Politeknik Kesehatan Makassar \\ Email: suhartatik2212@gmail.com
}

\begin{abstract}
Diabetic Ulcers was a threat to people with Diabetes Mellitus and even caused amputations. The purpose of this study was to determine the relationship between risk factors and the occurrence of Diabetes Ulcers to the patients with type 2 Diabetes Mellitus at Syekh Hospital of Gowa Regency. This study was an Analytical Survey Study that the researcher conducted a cross-sectional study conducted from April to May 2019. The population in this study was Type 2 of DM patients seeking treatment at Syekh Yusuf Hospital Gowa Regency, consisted of 30 respondents. The results showed that age, duration of DM and adherence to taking medication had a significant relationship with the occurrence of Diabetes Ulcers in type 2 of DM patients. All factors had a value $<0.05$. It was expected that patients will always increase efforts to prevent the occurrence of Diabetic Ulcers through the prevention of various risk factors for Diabetic Ulcers in patients with type 2 Diabetes. So, this needed to be considered by health workers to pay attention to the risk factors. One of the factors that could be modified was medication adherence because it affected the patient's blood sugar levels that had impacted on the complications of Diabetic Ulcers.
\end{abstract}

Keywords: Age, Length of Suffering from Diabetes Mellitus, Compliance with Taking Medication, Diabetic Ulcer

\section{ABSTRAK}

Ulkus diabetik merupakan salah satu ancaman pada penderita Diabetes Melitus (DM) bahkan dapat menyebabkan amputasi. Tujuan dari penelitian ini adalah mengetahui hubungan antara faktor resiko dengan terjadinya ulkus diabetik pada penderita diabetes melitus tipe 2 di RSUD Syekh Kabupaten Gowa. Penelitian ini adalah penelitian survey analitik, dimana peneliti akan melakukan penelitian dengan pendekatan cross sectional yang dilaksanakan pada bulan April - Mei 2019. Populasi dalam penelitian ini adalah pasien DM Tipe 2 yang berobat di RSUD Syekh Yusuf Kabupaten Gowa, dengan jumlah responden 30 orang. Hasil penelitian menunjukan faktor usia, lama menderita DM dan kepatuhan minum obat memiliki hubungan yang signifikan dengan terjadinya ulkus diabetik pasien diabetes melitus tipe 2. Seluruh faktor memiliki value $<0,05$. Diharapkan bagi penderita agar selalu meningkatkan upaya pencegahan terjadinya ulkus diabetik melalui pencegahan berbagai faktor resiko terjadinya ulkus diabetik pada penderita DM tipe 2, sehingga hal ini perlu diperhatikan oleh petugas kesehatan agar memperhatikan faktor resiko salah satunya faktor yang dapat dimodifikasi yaitu kepatuhan minum obat karena berpengaruh terhadap kadar gula darah penderita yang akan berdampak pada terjadinya komplikasi ulkus diabetik.

Kata kunci: Usia, Lama Menderita DM, Kepatuhan Minum Obat, Ulkus Diabetik

\section{PENDAHULUAN}

Penyakit Tidak Menular (PTM) sudah menjadi masalah kesehatan masyarakat, baik secara global, regional, nasional dan lokal. Salah satu penyakit tidak menular yang menyita banyak perhatian adalah Diabetes Melitus (DM). Diabetes Melitus merupakan penyakit kronis yang terjadi ketika pankreas tidak menghasilkan insulin yang cukup atau ketika tubuh tidak dapat secara efektif menggunakan insulin yang dihasilkan (WHO, 2015).

International Diabetes Federation (IDF, 2015), menyatakan terdapat 415 juta orang yang hidup dengan Diabetes di dunia pada tahun 2015. Selain itu adapun estimasi terakhir dari International Diabetes Federation (IDF, 2017) yang menyatakan terdapat 425 juta orang yang berusia kisaran 20-79 tahun yang hidup dengan Diabetes Melitus di dunia pada tahun 2017. Berdasarkan data diatas penyakit Diabetes Melitus pada tahun 2015 hanya terdapat 415 juta orang dan mengalami peningkatan pada tahun 2017 menjadi 425 juta orang.

Diabetes Melitus tanpa pengelolaan diri yang baik akan berkembang menjadi penyakit yang bersifat tahunan dan akan menyebabkan komplikasi seperti timbulnya gangren (S.Kirana et al., 2019). Pada tahun 2015 (IDF, 2015) penduduk Amerika yang berusia kisaran 20-79 tahun yang menderita Diabetes Melitus sebanyak 44,3 juta orang dan mengalami peningkatan pada tahun 2017 sebanyak 46 juta orang. Disusul oleh negara wilayah Asia, pada tahun 2015 penduduk Asia Tenggara berusia kisaran 20-79 tahun yang menderita Diabetes Melitus sebanyak 78 juta orang dan juga mengalami 
peningkatan pada tahun 2017 sebanyak 82 juta orang. Di India penderita Diabetes Melitus sebanyak 72,9 juta orang dan merupakan negara dimana rumah bagi jumlah orang dewasa terbesar kedua yang hidup dengan diabetes di seluruh dunia, setelah China (114,4 juta orang) (IDF, 2017).

Penyakit mematikan ini masih menjadi persoalan serius dunia, termasuk Indonesia. Indonesia merupakan salah satu negara berkembang di dunia bagian Asia Tenggara dan mengalami peningkatan jumlah penderita Diabetes Melitus. Di tahun yang sama 2015, Indonesia menempati peringkat ke tujuh di dunia untuk prevalensi penderita diabetes tertinggi di dunia bersama dengan China, India, Amerika Serikat, Brazil, Rusia dan Meksiko dengan jumlah estimasi orang dengan diabetes sebesar 10 juta orang. (WHO, 2015). Pada tahun 2017 terjadi peningkatan dimana jumlah penderita diabetes di Indonesia menempati peringkat ke-6 dengan prevalensi penderita Diabetes Melitus usia 20-79 tahun pada tahun 2017 mencapai 10,3 juta orang dan diperkirakan akan meningkat pada tahun 2045 menjadi 16,7 juta orang, ini setelah China, India, Amerika Serikat, Brazil, dan Meksiko (IDF, 2017).

Menurut Riskesdas 2018 menunjukkan prevalensi Penyakit Tidak Menular (PTM) salah satunya adalah Diabetes Melitus mengalami kenaikan jika dibandingkan dengan Riskesdas 2013, prevalensi berdasarkan pemeriksaan gula darah, diabetes mellitus naik dari $6,9 \%$ menjadi $8,5 \%$. Kenaikan prevalensi penyakit tidak menular ini berhubungan dengan pola hidup, antara lain merokok, aktivitas fisik dan konsumsi buah dan sayur (Riskesdas, 2018).

Indonesia terdiri dari 34 provinsi, salah satunya yaitu Provinsi Sulawesi Selatan dengan jumlah penduduk 8.690.294 orang (Kemenkes RI, 2017). Berdasarkan data Survailans Penyakit tidak menular Bidang P2PL (Pengendalian Penyakit dan Penyehatan Lingkungan) Dinas Kesehatan Provinsi Sulawesi Selatan tahun 2014 terdapat Diabetes Melitus 27.470 kasus baru, 66.780 kasus lama dengan 747 kematian. Prevalensi diabetes di Sulawesi Selatan yang didiagnosis dokter sebesar 1,6 persen. Diabetes Melitus yang didiagnosis dokter atau berdasarkan gejala sebesar 3,4 persen. Prevalensi diabetes yang didiagnosis dokter tertinggi terdapat di Kabupaten Pinrang (2,8\%), Kota Makassar $(2,5 \%)$, Kabupaten Toraja Utara $(2,3 \%)$ dan Kota Palopo (2,1\%). Prevalensi diabetes yang didiagnosis dokter atau berdasarkan gejala, tertinggi di Kabupaten Tana Toraja $(6,1 \%)$, Kota Makassar $(5,3 \%)$, Kabupaten Luwu $(5,2 \%)$ dan Kabupaten Luwu Utara $(4,0 \%)$. Berdasarkan data dari rekam medik di RSUD Syekh Yusuf Kabupaten Gowa menunjukkan bahwa jumlah penderita Diabetes Melitus yang berkunjung pada bulan Januari 2019 sebanyak 54 orang.

Peningkatan jumlah penderita Diabetes Melitus menyebabkan angka kejadian komplikasi juga akan semakin meningkat, satu diantaranya adalah kaki diabetik (Safitri, Hartati, \& Pratama, 2015). Penyakit diabetes dibagi atas 2 tipe, yakni tipe dapat menyebabkan perubahan patofisiologi pada berbagai sistem organ seperti mata, ginjal, ekstremitas bawah. Salah satu akibat komplikasi kronik atau jangka panjang penyakit ini adalah ulkus diabetikum (Rosa, Afriant, \& Edward, 2015). Hal yang sama pun diutarakan oleh (Kirana, Udiyono, Kusariana, \& Saraswati, 2019) dalam penelitiannya Diabetes Melitus tanpa pengelolaan diri yang baik akan berkembang menjadi penyakit yang bersifat tahunan dan akan menyebabkan komplikasi seperti timbulnya gangren. Permasalahan yang timbul di kaki dapat mengakibatkan amputasi hingga kematian jika tidak dilakukan pencegahan sejak penderita terdiagnosa diabetes melitus.

Adapun harapan pemerintah untuk mengurangi kejadian penyakit Diabetes Melitus yaitu dengan deteksi dini yang harus dilakukan secara proaktif dengan mendatangi sasaran, karena sebagian besar tidak mengetahui bahwa dirinya menderita penyakit tidak menular (Kemenkes Rl, 2015). Juga bagaimana masyarakat mampu mengenal faktor resiko yang dapat memicu terjadinya ulkus diabetik seperti faktor usia, jenis kelamin, lama menderita DM, kepatuhan minum obat, aktivitas fisik dan perawatan kaki.

Berdasarkan latar belakang diatas dan didapatkan masih tingginya jumlah kunjungan pasien diabetes, sehingga peneliti memilih RSUD Syekh Yusuf Gowa sebagai tempat penelitian tentang "Faktor Resiko Yang Berhubungan Dengan Terjadinya Ulkus Diabetik Pada Penderita Diabetes Melitus Tipe 2".

\section{METODE}

\section{Desain, tempat dan waktu}

Penelitian ini adalah penelitian survei analitik, dimana peneliti akan melakukan penelitian dengan pendekatan cross sectional. Dalam penelitian ini, peneliti menyelidiki beberapa faktor yang berhubungan dengan terjadinya ulkus diabetik pada penderita Diabetes Melitus Tipe 2 di RSUD Syekh Yusuf Kabupaten Gowa. Penelitian ini dilaksanakan pada tanggaal 29 April sampai dengan 31 Mei 2019 di RSUD Syekh Yusuf Kabupaten Gowa.

Setelah dilakukan pengumpulan data, kemudian dilakukan analisis data untuk mengetahui hubungan usia, lama menderita DM dan kepatuhan minum obat dengan terjadinya ulkus diabetik menggunakan uji statistik Chi-Square dengan melihat dari nilai OR (Odd Ratio). 
Jumlah dan cara pengambilan subjek Jumlah sampel dalam penelitian ini adalah 30 orang. Teknik pengambilan sampel yang digunakan adalah purposive sampling dimana besar sampel tergantung jumlah yang dibutuhkan oleh peneliti dan memenuhi kriteria inklusi dan eksklusi.

HASIL

\section{Tabel 1.Karakteristik Responden Penderita Diabetes Melitus di RSUD Syekh Yusuf Kabupaten Gowa pada tahun 2019}

\begin{tabular}{lcc}
\hline Karakteristik Sampel & \multicolumn{2}{c}{ Jumlah } \\
\cline { 2 - 3 } & $\mathbf{f}$ & $\%$ \\
\hline Usia & & \\
Dewasa Muda & 11 & 36,7 \\
$\quad$ Dewasa Tua & 19 & 63,3 \\
\hline Jenis Kelamin & & \\
$\quad$ Laki-laki & 8 & 26,7 \\
$\quad$ Perempuan & 22 & 73,3 \\
\hline Tingkat Pendidikan & & \\
Tidak Sekolah & 4 & 13.3 \\
SD & 11 & 36,7 \\
SMP & 8 & 26,7 \\
SMA & 6 & 20 \\
S1 & 1 & 33,3 \\
\hline Pekerjaan & & \\
PNS & 1 & 3,3 \\
Wiraswata & 3 & 10 \\
Karyawan & 1 & 3.3 \\
Buruh & 3 & 10 \\
Petani & 4 & 13,3 \\
IRT & 18 & 60 \\
\hline Jenis Obat & & \\
Metformin & 24 & 80 \\
Glibenklamid & 2 & 6,7 \\
Metformin, & 4 & 13,3 \\
Glibenklamid & & \\
\hline
\end{tabular}

Tabel 1 menunjukkan lebih dari separuh responden berusia dewasa tua sebanyak 19 orang $(63,3 \%)$. Sebagian besar responden berjenis kelamin perempuan yaitu sebanyak 22 orang $(73,3 \%)$. Berdasarkan tingkat pendidikan responden yang memiliki riwayat pendidikan SD yaitu 11 orang $(36,7 \%)$. Responden IRT sebanyak 18 orang $(60 \%)$. Jenis obat DM yang dikonsumsi adalah metformin sebanyak 24 orang $(80 \%)$.
Tabel 2. Distribusi Frekuensi Responden Berdasarkan Lama Menderita DM di RSUD Syekh Yusuf Kabupaten Gowa

\begin{tabular}{c|cc}
\hline \multirow{2}{*}{ Lama Menderita DM } & \multicolumn{2}{|c}{ Jumlah } \\
\cline { 2 - 3 } & $\mathbf{f}$ & $\%$ \\
\hline Baru (<5 tahun) & 17 & 56.7 \\
Lama ( $\geq 5$ tahun) & 13 & 43.3 \\
\hline Total & $\mathbf{3 0}$ & $\mathbf{1 0 0}$ \\
\hline
\end{tabular}

Berdasarkan tabel 2 diatas dapat diketahui bahwa sebagian besar responden DM baru menderita Diabetes Melitus ( $\geq 5$ tahun), yakni sebanyak 17 orang $(56.7 \%)$ dan yang telah lama menderita Diabetes Melitus $(<5$ tahun) yakni sebanyak 13 orang (43.3\%).

Tabel 3. Distribusi Frekuensi Responden Berdasarkan Kepatuhan Minum Obat di RSUD Syekh Yusuf Kabupaten Gowa

\begin{tabular}{c|cc}
\hline Kepatuhan Minum & \multicolumn{2}{|c}{ Jumlah } \\
\cline { 2 - 3 } Obat & $\mathbf{f}$ & $\%$ \\
\hline Patuh & 21 & 70 \\
Tidak Patuh & 9 & 30 \\
\hline Total & 30 & 100 \\
\hline
\end{tabular}

Berdasarkan tabel 3 diatas dapat diketahui bahwa sebagian besar responden DM patuh dalam minum obat, yakni sebanyak 21 orang $(70 \%)$ dan tidak patuh sebanyak 9 orang (30\%).

Tabel 4. Distribusi Frekuensi Responden Berdasarkan Terjadinya Ulkus Diabetik di RSUD Syekh Yusuf Kabupaten Gowa

\begin{tabular}{c|cc}
\hline Terjadinya Ulkus & \multicolumn{2}{|c}{ Jumlah } \\
\cline { 2 - 3 } Diabetik & $\mathbf{f}$ & $\%$ \\
\hline Tidak Ada Ulkus & 15 & 50 \\
Ada Ulkus & 15 & 50 \\
\hline Total & $\mathbf{3 0}$ & $\mathbf{1 0 0}$ \\
\hline
\end{tabular}

Berdasarkan tabel 4 diatas dapat diketahui bahwa responden yang mengalami ulkus dan tidak mengalami ulkus sama besar, yakni $50 \%$. 
Tabel 5. Hubungan Usia dengan Terjadinya Ulkus Diabetik pada Penderita DM di RSUD Syekh Yusuf Kabupaten Gowa

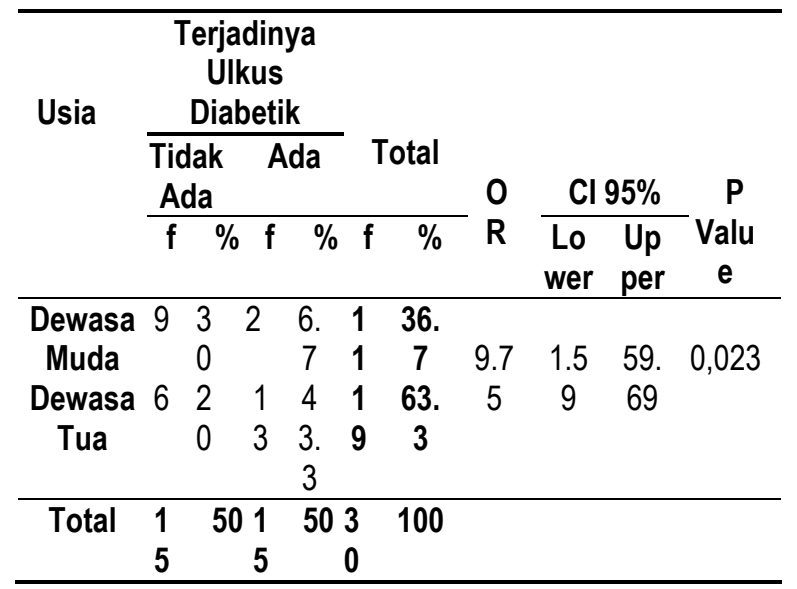

Berdasarkan tabel 5 diatas dapat diperoleh hasil bahwa proporsi pasien DM tipe 2 yang mengalami ulkus diabetik lebih banyak terjadi pada usia dewasa tua, yakni $43.3 \%$. Hasil uji statistik menunjukkan adanya hubungan signifikan antara usia dengan terjadinya ulkus diabetik, nilai $P$ Value $=0,023(P<0,050)$ dengan nilai $O R 9.75$ yang artinya pasien DM dengan usia dewasa tua mempunyai risiko 9 kali lebih besar untuk mengalami ulkus diabetik dibanding dewasa muda. Maka disimpulkan Ho diterima dan Ha ditolak.

Tabel 6. Hubungan Lama Menderita DM dengan Terjadinya Ulkus Diabetik pada Penderita DM di RSUD Syekh Yusuf Kabupaten Gowa

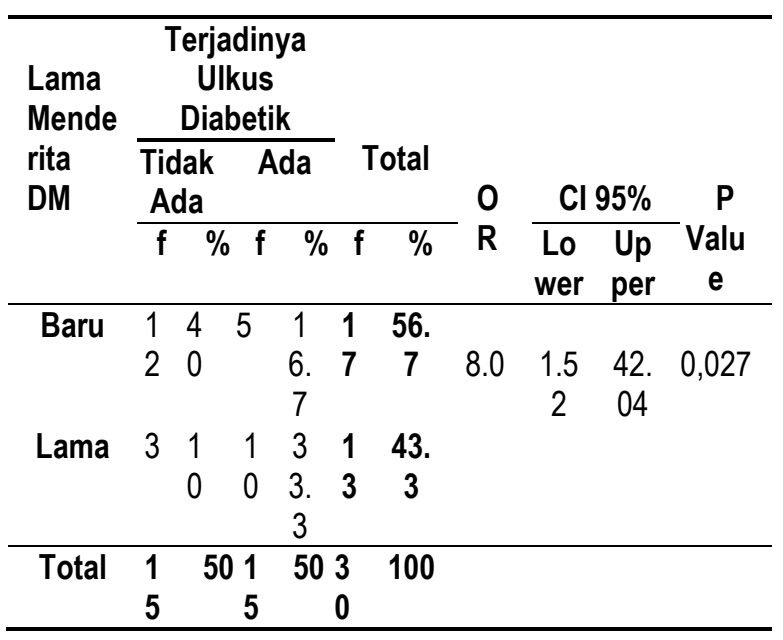

Berdasarkan tabel 6 diatas diperoleh hasil bahwa responden yang lama menderita DM cenderung lebih banyak mengalami ulkus diabetik yakni sebesar 33.3\% dibandingkan dengan pasien yang baru menderita DM. Hasil analisis lebih lanjut didapatkan ada hubungan yang signifikan antara lama menderita DM dengan terjadinya ulkus diabetik dengan nilai $P=0,027 \quad(P<0,050)$ dengan nilai $O R$ 8.0 yang artinya pasien yang lama menderita DM mempunyai risiko 8 kali lebih besar untuk mengalami ulkus diabetik dibanding yang baru menderita. Maka disimpulkan Ho diterima dan Ha ditolak.

Tabel 7. Hubungan Kepatuhan Minum Obat dengan Terjadinya Ulkus Diabetik pada Penderita DM di RSUD Syekh Yusuf Kabupaten Gowa

\begin{tabular}{|c|c|c|c|c|c|c|c|c|}
\hline \multirow{3}{*}{$\begin{array}{l}\text { Kepat } \\
\text { uhan }\end{array}$} & \multicolumn{3}{|c|}{$\begin{array}{c}\text { Terjadinya } \\
\text { Ulkus } \\
\text { Diabetik }\end{array}$} & \multirow[b]{2}{*}{ Total } & \multirow{3}{*}{$\begin{array}{l}0 \\
R\end{array}$} & & & \multirow{3}{*}{$\begin{array}{c}P \\
\text { Valu } \\
\text { e }\end{array}$} \\
\hline & $\begin{array}{l}\text { Tidak } \\
\text { Ada } \\
\end{array}$ & \multicolumn{2}{|c|}{ Ada } & & & \multicolumn{2}{|c|}{ Cl 95\% } & \\
\hline & & $f$ & $\%$ & f $\%$ & & $\begin{array}{l}\text { Lo } \\
\text { wer }\end{array}$ & $\begin{array}{l}\text { Up } \\
\text { per }\end{array}$ & \\
\hline Patuh & $\begin{array}{ll}1 & 4 \\
4 & 6 . \\
& 7\end{array}$ & 7 & $\begin{array}{l}2 \\
3 . \\
3\end{array}$ & $\begin{array}{ll}2 & 70 \\
1 & \end{array}$ & $\begin{array}{c}16 . \\
0\end{array}$ & $\begin{array}{c}1.6 \\
5\end{array}$ & $\begin{array}{c}154 \\
.59\end{array}$ & 0,014 \\
\hline $\begin{array}{l}\text { Tidak } \\
\text { Patuh }\end{array}$ & $\begin{array}{c}13 . \\
3\end{array}$ & 8 & $\begin{array}{l}2 \\
6 . \\
7\end{array}$ & 30 & & & & \\
\hline Total & $\begin{array}{ll}1 & 5 \\
5 & \end{array}$ & $\begin{array}{l}1 \\
5\end{array}$ & 50 & 100 & & & & \\
\hline
\end{tabular}

Berdasarkan tabel 7 diatas diperoleh hasil bahwa responden yang patuh minum obat cenderung lebih banyak tidak mengalami ulkus diabetik yakni sebesar $46.7 \%$ dibandingkan dengan pasien yang tidak patuh minum obat. Hasil analisis lebih lanjut didapatkan ada hubungan yang signifikan antara kepatuhan minum obat dengan terjadinya ulkus diabetik dengan nilai $P=0,014(P<0,050)$ dengan nilai OR 16.0 yang artinya pasien yang patuh minum obat mempunyai risiko 16 kali lebih besar untuk tidak mengalami ulkus diabetik dibanding yang tidak patuh minum obat. Maka disimpulkan $\mathrm{Ho}$ diterima dan $\mathrm{Ha}$ ditolak.

\section{PEMBAHASAN}

Karakteristik Responden Penderita Diabetes Melitus di RSUD Syekh Yusuf Kabupaten Gowa pada tahun 2019

Hasil penelitian menunjukkan bahwa penderita diabetes melitus tipe 2 di RSUD Syekh Yusuf Kabupaten Gowa rata-rata berusia $46-\geq 65$ tahun sebanyak 19 orang (63.3\%) dan yang berusia 26 - 45 tahun sebanyak 11 orang (36.7\%).

Hasil penelitian menunjukkan bahwa penderita diabetes melitus tipe 2 di RSUD Syekh Yusuf Kabupaten Gowa sebagian besar berjenis 
kelamin perempuan sebanyak 22 orang $(73.3 \%)$ dan sebagian kecil berjenis kelamin laki-laki sebanyak 8 orang (26.7\%).

Hasil penelitian menunjukkan bahwa penderita diabetes melitus tipe 2 di RSUD Syekh Yusuf Kabupaten Gowa untuk tingkat pendidikan yaitu tidak sekolah sebanyak 4 orang (13.3\%), lulusan SD sebanyak 11 orang (36.7\%), lulusan SMP sebanyak 8 orang $(26.7 \%)$, lulusan SMA sebanyak 6 orang $(20 \%)$ dan lulusan S1 sebanyak 1 orang $(3.3 \%)$.

Hasil penelitian menunjukkan bahwa penderita diabetes melitus tipe 2 di RSUD Syekh Yusuf Kabupaten Gowa untuk rerata pekerjaan yaitu PNS sebanyak 1 orang (3.3\%), Wiraswasta sebanyak 3 orang (10\%), Karyawan sebanyak 1 orang $(3.3 \%)$, buruh sebanyak 3 orang $(10 \%)$ dan IRT sebanyak 18 orang (60\%).

Hasil penelitian menunjukkan bahwa penderita diabetes melitus tipe 2 di RSUD Syekh Yusuf Kabupaten Gowa untuk rerata jenis obat yaitu metformin sebanyak 24 orang (80\%), glibenklamid 2 orang $(6.7 \%)$ dan keduanya digabungkan metformin dan glibenklamid sebanyak 4 orang (13.3\%).

\section{Hubungan Usia dengan Terjadinya Ulkus Diabetik pada Penderita DM di RSUD Syekh Yusuf Kabupaten Gowa}

Berdasarkan hasil uji Chi-Square diperoleh hasil bahwa semakin tinggi usia responden maka semakin lebih cenderung mengalami ulkus diabetik. Perbandingannya yaitu dewasa tua dengan adanya ulkus diabetik sebanyak 13 orang (43.3\%) dan tidak ada ulkus diabetik 6 orang $(20 \%)$, dan dewasa muda yang mengalami ulkus diabetik sebanyak 2 orang $(6.7 \%)$ dan tidak mengalami ulkus diabetik sebanyak 9 orang $(30 \%)$. Dengan diperoleh nilai $\mathrm{P}=0,023$ menunjukan bahwa ada hubungan yang signifikan antara usia dengan terjadinya ulkus diabetik pada penderita DM tipe 2.

Hasil penelitian ini didukung oleh (Kirana et al., 2019) usia $>55$ tahun memiliki risiko sebesar 1,8 kali lebih tinggi untuk mengalami komplikasi gangren diabetik daripada usia $<55$ tahun.

Hal ini sesuai dengan teori Singh et al., (2005 dalam Supriyadi, 2017) yang menyatakan bahwa proses aging menyebabkan penurunan sekresi atau resistensi insulin yang akan mempengaruhi penurunan sirkulasi darah salah satunya pembuluh darah besar atau sedang di tungkai yang lebih mudah terjadi ulkus diabetik. Penderita diabetes memiliki resiko untuk terjadinya ulkus pada kaki sebesar $15 \%$ sepanjang hidupnya. Hal ini bisa terjadi dua kali lipat lebih banyak dari penderita diabetes dibandingkan non diabetes.

\section{Hubungan Lama Menderita DM dengan Terjadinya Ulkus Diabetik pada Penderita DM di RSUD Syekh Yusuf Kabupaten Gowa}

Berdasarkan hasil uji Chi-Square diperoleh hasil bahwa persentasi responden lama menderita DM lebih besar untuk mengalami ulkus diabetik dibanding yang baru menderita DM. Responden yang lama menderita DM yang mengalami ulkus diabetik sebanyak 10 orang $(33.3 \%)$ dan tidak mengalami ulkus diabetik sebanyak 3 orang (10\%), sedangkan responden yang baru menderita DM yang tidak mengalami ulkus diabetik sebanyak 12 orang (40\%) dan yang mengalami ulkus diabetik sebanyak 5 orang $(16,7 \%)$. Dengan diperoleh nilai $\mathrm{P}=0,027$ $(<0,05)$ menunjukan bahwa ada hubungan yang signifikan antara lama menderita DM dengan terjadinya ulkus diabetik pada penderita DM tipe 2.

Hasil penelitian ini didukung oleh (Kirana et al., 2019) sebagian besar responden yang memiliki gangren diabetik telah menderita diabetes melitus $>5$ tahun. Hal ini juga didukung oleh nilai $\mathrm{OR}=4,333$ $(95 \% \mathrm{Cl} 1,569-11,967)$ yang menyatakan bahwa lama menderita diabetes mellitus $>5$ tahun memiliki risiko 4,3 kali lebih besar untuk terkena gangren diabetik daripada responden yang menderita diabetes mellitus $<5$ tahun.

Hal ini sesuai dengan teori Smeltzer et al (2010 dalam Srimiyati, 2018) prevalensi neuropati meningkat bersamaan dengan bertambahnya usia dan lamanya penyakit.

\section{Hubungan Kepatuhan Minum Obat dengan Terjadinya Ulkus Diabetik pada Penderita DM di RSUD Syekh Yusuf Kabupaten Gowa}

Berdasarkan hasil uji Chi-Square diperoleh hasil bahwa persentasi responden yang patuh minum obat lebih banyak yang tidak mengalami ulkus diabetik dibanding yang tidak patuh minum obat. Responden yang patuh minum obat dan tidak mengalami ulkus diabetik sebanyak 14 orang $(46.7 \%)$ dan yang mengalami ulkus diabetik sebanyak 7 orang $(23.3 \%)$, sedangkan responden yang tidak patuh minum obat dan mengalami ulkus diabetik sebanyak 8 orang $(26.7 \%)$ dan yang tidak mengalami ulkus diabetik sebanyak 1 orang (3.3\%). Dengan diperoleh nilai $\mathrm{P}=0,014 \quad(<0,05)$ menunjukan bahwa ada hubungan yang signifikan antara kepatuhan minum obat dengan terjadinya ulkus diabetik pada penderita DM tipe 2 .

Hasil penelitian ini didukung oleh penelitian dari (Nanda, etc al. 2018) bahwa semakin patuh pasien dalam minum obat anti diabetik, gula darahnya akan semakin terkontrol, namun jika pasien tidak patuh dalam minum obat anti diabetik maka sebaliknya, gula darahnya menjadi tidak terkontrol. Hal tersebut dapat menjadi acuan apabila gula darah 
terkendali maka resiko untuk mengalami komplikasi pun dapat dicegah.

Penelitian lainnya dari (Cristanti, 2017) bahwa terdapat hubungan antara kepatuhan minum obat dengan kejadian neuropati, jika dilihat secara rinci responden dengan kepatuhan minum obat rendah mengalami kejadian neuropati yang tinggi.

Hal ini sesuai dengan hasil penelitian dari (Nanda, Wiryanto, \& Triyono, 2018) bahwa semakin patuh pasien dalam minum obat anti diabetik, gula darahnya akan semakin terkontrol, namun jika pasien tidak patuh dalam minum obat anti diabetik maka sebaliknya, gula darahnya menjadi tidak terkontrol.

\section{KESIMPULAN}

Hasil uji menunjukkan Ha diterima, artinya ada hubungan yang bermakna antara usia, lama menderita DM dan Kepatuhan minum obat dengan terjadinya ulkus diabetik di RSUD Syekh Yusuf Kabupaten Gowa. Semakin tinggi usia seorang penderita DM maka semakin tinggi pula resiko untuk mengalami komplikasi ulkus diabetik.

\section{SARAN}

1. Bagi penderita diharapkan agar selalu meningkatkan upaya pencegahan terjadinya ulkus diabetik melalui pencegahan berbagai faktor resiko terjadinya ulkus diabetik pada penderita DM tipe 2.

2. Bagi keluarga diharapkan agar memperhatikan faktor resiko salah satunya faktor yang dapat dimodifikasi yaitu kepatuhan minum obat karena berpengaruh terhadap kadar gula darah penderita yang akan berdampak pada terjadinya komplikasi ulkus diabetik.

3. Bagi petugas kesehatan diharapkan agar memperhatikan faktor resiko salah satunya faktor yang dapat dimodifikasi yaitu kepatuhan minum obat karena berpengaruh terhadap kadar gula darah penderita yang akan berdampak pada terjadinya komplikasi ulkus diabetik.

4. Bagi peneliti selanjutnya diharapkan perlu melakukan penelitian dengan menggunakan variabel yang lain dan mengembangkan penelitian ini agar penelitian mengenai faktor resiko komplikasi ulkus diabetik pasien DM tipe 2 memiliki hasil lebih optimal.

\section{DAFTAR PUSTAKA}

Cristanti. (2017). Kepatuhan Diet Dan Minum Obat Dengan Kejadian Neuropati Pada Diabetes Melitus Tipe 2. Universitas Muhammadiyah, 2(4), 1-12. https://doi.org/http://repository.umy.ac.id/handle/123456789/15588

IDF. (2015). International Diabetes Atlas. (IDF, Ed.), International Diabetes Federation. https://doi.org/https://www.oedg.at/pdf/1606_IDF_Atlas_2015_UK.pdf

IDF. (2017). Online Version Of DIABETES ATLAS Eight Edition 2017. http://diabetesasia.org/content/diabetes_guidelines/IDF_guidelines.pdf

Kemenkes RI. (2015). Rencana Strategis Kementerian Kesehatan Tahun 2015-2019. Kementerian Kesehatan RI, 1228. https://doi.org/http://www.infodev.org/en/Publication.20.html

Kemenkes RI. (2017). Pusat Data dan Informasi Kemenkes RI, 17. https://doi.org/www.depkes.go.id/folder/view/01/structure-publikasi-data-pusat-data-dan-informasi.html

Kirana, S., Udiyono, A., Kusariana, N., \& Saraswati, L. D. (2019). Faktor-Faktor Yang Berhubungan Dengan Timbulnya Gangren Pada Pasien Diabetes Mellitus Di RSUD K.R.M.T. Wongsonegoro Semarang. Jurnal Kesehatan Masyarakat (e-Journal), 1(1), 192-202. https://doi.org/https://ejournal3.undip.ac.id/index.php/jkm/article/view/22869

Nanda, O. D., Wiryanto, B., \& Triyono, E. A. (2018). Hubungan Kepatuhan Minum Obat Anti Diabetik dengan Regulasi Kadar Gula Darah pada Pasien Perempuan Diabetes Mellitus. Amerta Nutrition, 2(4), 340-348. https://doi.org/10.20473/amnt.v2i4.2018.340-348

Riskesdas. (2018). Hasil Utama Riskesdas 2018. Kesehatan Masyarakat Nasional, 56-58.

Rosa, R. L., Afriant, R., \& Edward, Z. (2015). Faktor Risiko Terjadinya Ulkus Diabetikum pada Pasien Diabetes Mellitus yang Dirawat Jalan dan Inap di RSUP Dr . M . Djamil dan RSI Ibnu Sina Padang. Jurnal Kesehatan Andalas, 4(1), 243-248. https://doi.org/10.1080/09654310124479 
Jurnal Media Keperawatan: Politeknik Kesehatan Makassar

Vol. 11 No. 012020

e-issn : 2622-0148, p-issn : 2087-0035

Safitri, K. H., Hartati, M. S., \& Pratama, A. (2015). Karakteristik Responden Penderita Diabetes Melitus Tipe 2 Dengan Resiko Kaki Diabetik. Kesehatan Masyarakat, 1-7. https://doi.org/https://media.neliti.com/media/publications/197276-ID-karakteristik-ulkus-diabetikum-padapend.pdf

Srimiyati. (2018). Pengetahuan Pencegahan Kaki Diabetik Penderita Diabetes Melitus Berpengaruh Terhadap $\begin{array}{llll}\text { Perawatan Kaki. } & \text { Medisains, } & \text { 76-82), }\end{array}$ https://doi.org/jurnalnasional.ump.ac.id/index.php/medisains/article/../2066

Supriyadi. (2017). Panduan Praktis Skrinning Kaki Diabetes Mellitus. Yogyakarta: Deepublish

WHO. (2015). World Hearth Organization. Epidemiological Situation. https://doi.org/https://www.who.int/leishmaniasis/burden/en/ 